\title{
AC 2007-640: MECHANICAL ENGINEERING STUDY ABROAD PROGRAMS IN GERMANY - EXPERIENCES AND LESSONS LEARNED
}

\section{Raghu Echempati, Kettering University}

RAGHU ECHEMPATI is a Professor of Mechanical Engineering at Kettering University (formerly GMI Engineering \& Management Institute). He has over 20 years of teaching, research and consulting experience. His teaching and research interests are in the areas of Mechanics, Machine design, and CAE (including metal forming simulation and Design of Machines and Mechanisms). He is very active in the Study Abroad Programs at Kettering University. He is a member of ASME, ASEE, and SAE, and a Fellow of the ASME.

\section{Butsch Michael, FH-Konstanz, Germany}

MICHAEL BUTSCH is a professor of Mechanical Engineering at FH-Konstanz in Germany. He is very active in the international exchange programs with many European, Asian and U.S. Universities. His area of teaching and research interest is Automotive Powertrains. 


\title{
Mechanical Engineering Study Abroad program in Germany - Experiences and Lessons Learned
}

\begin{abstract}
This paper discusses the continued developments and the current status of study abroad programs for the mechanical engineering students at Kettering University. In particular, this paper outlines the study exchange with schools in Germany in which there is an equal number of students in exchange over two or three year span between the Kettering University and the participating schools in Germany. Also, this paper discusses in detail about the assessment and evaluation tools for study abroad programs. Programs at other countries such as Australia and Mexico are also available to the Kettering University students, while efforts are under way to explore opportunities in other parts of Europe and in Asia. Such study abroad programs provide an opportunity and promote understanding across technical programs and other nations.
\end{abstract}

Kettering University's engineering academic and cooperative education make it unique among Engineering Schools in the United States. One of the main purposes of the international programs is to provide students value-added technical and cultural experiences. It has been well documented that engineering students who have international study experience are more likely to be hired and prepared for the global market place. During the last three years, the Kettering University study abroad programs have been steadily growing with over 90 engineering students per year participating in study abroad programs in Germany alone. Under these study programs, the students typically live abroad for three to six months and interact with other international students, professors and in some cases industry employers from different cultures and academic and industrial traditions. Students return from these experiences feeling happy, confident and knowledgeable about the world in addition to having a broader technical understanding of their fields of study.

This paper will discuss the current process at Kettering University of setting up of study abroad programs, new international programs structure, course mapping and course equivalency, students' advisement, grading differences, student expectations, role of the faculty advisors, program assessment and finally, the lessons learned for continuous improvements of such programs. Technical Universities that wish to start new study abroad programs and those who already have study exchange in place would benefit from the experiences, findings and recommendations presented in this paper.

\section{Introduction}

The status of Kettering University's study abroad programs was discussed and presented at one of the earlier ASEE conferences ${ }^{1}$. That paper documented the development and implementation of study-abroad programs for engineers and also the evaluation process of these programs 
followed at that time. The purpose of these International Programs is to provide students valueadded technical and cultural experiences. Study-abroad is an investment in the future and prestige of the University and an excellent way for students to gain technical and cultural expertise. Under this program, the students live abroad for three months and interact with other students and professors from different cultures and academic traditions.

Up until the end of year 2006, there used to be three main International Activities at Kettering University: a) Study Abroad for Kettering University students, b) Study at Kettering University for Foreign Exchange students and c) Matriculating foreign students at Kettering University. The first of these activities used to occur in the Academic Services Office on the Academic side of Kettering University. This office deals strictly with the preparation and organization of study abroad programs. At Kettering University foreign students used to be handled out of a separate office called the Office of International and Governmental Affairs. This office is responsible for the preparation and organization of the incoming students from abroad to Kettering University. From a federal government perspective, there needs to be a rough balance of the number of students between the first two categories in order to maintain the exchange. Finally, there are degree-seeking and tuition paying students from abroad who study at Kettering as full-time students. The Office of Enrollment Management used to handle all such students in this category. With the new administration at Kettering University, all these three categories are being consolidated in to one unit and a new structure of International Programs is being emerged. Key elements of this newly proposed international programs structure is shown in Figure 1. The proposed International Programs Director position is to be headed by an internal faculty with half time teaching load. This person reports directly to the Provost.

To sustain Kettering University's study abroad programs and to have them continue to grow and develop, we will need to examine our International Programs to see what needs improvement, what lessons have we learned in running study abroad programs and examine if there are other ways of cultural exchange for faculty besides the students. Part of what we know lies in the literature in the field of International Education. An ever increasing body of literature suggests that evaluation and assessment of study abroad programs and faculty exchange will become increasingly important as we try to acquire funding from new sources and garner support from new academic disciplines. Careful review of programs will help both students and the faculty to nurture a respect for international exchange. Engineering students typically do not have the variety of International Program offerings as for example language or humanities students have. As a result, Engineering faculty and administration have less experience with study abroad than their counterparts in literature and letters. In addition, a good evaluative process for study abroad programs can help the University as a whole in the accreditation cycle and help student retention goals. This paper seeks to look at some of the developments in international programs at Kettering University, the reasons to assess and evaluate study abroad programs for engineers and look at some of the lessons we have learned. Fortunately, the author has several cycles (one term each time) of teaching and monitoring the exchange programs in Germany as a guest professor and hence has a first hand experience of the benefits and limitations of such study abroad programs. The next section deals with a brief review of relevant literature on study abroad programs. 


\section{Literature Review}

There are numerous articles on study abroad published by ASEE, The Chronicle of Higher Education $^{2}$ and many other international education sources like DAAD ${ }^{3}$, Institute of International Education $^{4}$ (IIE), etc. Only a few related references are mentioned in this paper and therefore the list is by no means complete. Study abroad programs and international educational experience in some form or the other have been in existence for many decades. Most recently, from around 1995 to 2000 , the number of U.S students studying abroad increased over $45 \%$ from nearly 90,000 to almost 130,000 students. Here at Kettering University, we have seen enrollment in study abroad programs in numbers from less than 20 to 80 students in the same period of time. Driving this trend is a strong commitment by the President of the University to increase numbers of students who study abroad in addition to the expectation among students that studying abroad is an integral and important part of their undergraduate education. Kettering University sends the majority of its students to Western Europe (mostly to Germany). While Americans who study abroad typically study in the humanities and social sciences, notable increases have been seen in business and technical fields such as engineering and in hard science fields.

The Bologna Declaration ${ }^{5}$ is a pledge by more than 29 countries to reform the structures of their higher education systems in a convergent way. The Declaration is a key document which marks a turning point in the development of European higher education. The Bologna Declaration is not a reform imposed upon national governments or higher education institutions. The Bologna process aims at creating convergence and, thus, is not a path towards the "standardisation" or "uniformisation" of European higher education. Therefore, the fundamental principles of autonomy and diversity are respected. The Declaration recognizes the value of coordinated reforms, compatible systems and common action.

Erasmus $^{6}$ ("European Community Action Scheme for the Mobility of University Students") is another program which seems to be one of the world's largest university exchange program which is in its 20's next year. Over a million students have taken part in this rewarding and challenging experience since it began in 1987. It involved over 2000 institutions in more than 30 countries. Erasmus scheme now covers over $90 \%$ of European higher education establishments. Since its modest start it has become hugely successful, broadening the horizons of all those involved. Above and beyond the direct learning experience, it creates a space for openness and tolerance and brings people together in a natural way. It promotes inter-cultural dialogue and encourages young people to think "European" - and to be mobile not just when studying, but also when entering the job market. Studies confirm that the Erasmus experience is considered valuable by employers, leading to better paid, more stable jobs. From next year until 2013, Erasmus will run under the new Lifelong Learning Program. The target is to involve over 3 million students by 2012, giving each the chance to experience life abroad. Erasmus's website provides more details about how it operates.

In 1998/99, 39\% of U.S. students who went abroad majored in the Social Sciences and Humanities and $17.7 \%$ toward degrees in Business. Engineering, Physical Sciences, Math, and 
computer Science combined for over $12 \%$ of the majors studying outside the USA during this time while majors in foreign languages have dropped to $8 \%$. Other trends in the past few years worthy of note are that the leading destinations for American study abroad students is shifting from Western European countries to locations such as Mexico, Australia, New Zealand, Costa Rica, Japan, and China. All of these countries have seen enrollment increases in American students interested in studying in these parts of the world. However, at Kettering University, majority of the study abroad students (around 90 to 100 per year) attend schools in Germany with two or three studying in Australia. The main reason for this is the matching of the study terms and the course offerings in Germany with Kettering University. Also, a few students get to work in Europe for one more term.

According to the Institute of International Education ${ }^{4}$, there are increases in student applications to study abroad such as: $55 \%$ increase in applications for scholarships of the National Security Education Program (NSEP) providing funding for students going to areas of the world such as Asia, Africa, the Middle East and Latin America, 10 to 15\% increase in Fulbright student applications and a 45\% increase in the IIE's Global Engineering Education Exchange. This last figure is what interests us as an engineering school in terms of how to capitalize on this increasing trend in International Engineering Educational exchanges.

In the years following September 11, 2001, safety has been one of the primary concerns of administrators involved in sending American students abroad. In the continuing debate over the future of International Study, one question that needs to be continuously addressed is how to judge and evaluate the merit and worth of study abroad programs. This question is crucial to ask now if we are going to build solid, and long-lasting technical exchange programs that win the respect of faculty, administrators, students and parents.

At the ASEE-2001 conference, many papers were presented on study abroad programs. Pathmomvanich and Najafi ${ }^{7}$ discussed the general benefits of such study abroad programs. Chen and Simmons ${ }^{8}$ in their paper discussed the issues concerning their proposed study abroad program between Southern University, Baton Rouge, Louisiana and Alexandria University in Egypt. Their collaboration was funded by USAID. Upadhyaya and Kerlin ${ }^{9}$ described the cyberlinked collaboration in their senior course on Introduction to Maintenance Engineering with two universities abroad: one in France and the other in Brazil. A set of guidelines was developed in order to successfully carry out the senior projects. Finally, they have discussed the challenges of cyber-linked projects, as well as the rewards, which outweigh the difficulties.

Mazumdar and Bean ${ }^{10}$ of the University of Michigan discussed the design, development, implementation and evaluation of a Global education program. Their program concentrates on students gaining knowledge and understanding about the exchange experiences in China, Mexico and UK. They referred to many US universities that have study abroad programs. Among these, the programs at the University of Rhode Island, Worcester Polytechnic Institute, the University of Illinois, the Georgia Institute of Technology, the University of Cincinnati, Kettering University and Clemson University are well established, particularly in engineering fields. Another such global engineering exchange program between Old Dominion University and Rajagiri College in Cochin, India is discussed by Chaturvedi, et $\mathrm{al}^{11,12}$. Their overall program is assessed for its 
benefits, efficiency and students understanding of the US and Indian university systems. Thompson and Sterkenburg ${ }^{13}$ of Aviation Technology at Perdue University discuss another international program in terms of the true meaning of global engineering as applied to their Aviation Technology program. At the ASEE 2002 Colloquium held in Berlin, Germany several papers on study abroad programs were presented. For example, refer to the paper by Rogers ${ }^{14}$, which outlines a program sponsored by SiemensWestinghouse with UCF, and the article Petersen et al $^{15}$ who discuss the ABET accreditation issues between the Milwaukee School of Engineering and Fachhochschule Luebeck in Germany. At the ASEE 2006 Conference Brito, et $\mathrm{al}^{16}$ who outlines their experience of holding several world conferences in Brazil on the scope and research in engineering education, Bohn and Hampe ${ }^{17}$ who discussed their ME study abroad programs.

At Kettering University, there are several steps followed to establish a new study exchange program that can take up to six months or more. The main steps involve identification of a list of courses taught in English and then getting the various approvals from within the university committees, including the senate. Students apply up to one year or more in advance to study abroad. They basically prepare their course plan for each of their academic terms until they graduate. Typically, they do study abroad during their Junior - II term. One of the main functions of the faculty advisor is to make sure that the courses offered at the host school transfer back (with a Pass or Fail grade). Due to high demand for study abroad in the Mechanical Engineering at Kettering, the minimum cumulative grade point to apply for study abroad as well as to pass a course at the host school has been raised from a mere Pass grade (D Grade) to Fair grade ( $\mathrm{C}$ grade). Currently, more than $80 \%$ applicants have their GPA above $90 \%$. Students typically take up to 16 credits (4 courses) including the social science course that is required to be taken whether for credit or for no credit. This social science course is called Germany With in Europe. With more and more countries joining the European Union, the importance of teaching this course becomes more essential for the American Students. As mentioned before, Figure 1 shows the new program structure at Kettering that becomes functional from mid-February of year 2007. This is a faculty-led program structure with the full time staff required to be knowledgeable about the governmental procedures. With this new program structure, new ways of faculty-led study abroad programs are being investigated at Kettering University. One of the examples of such faculty-led study abroad programs is offered by Bradley University ${ }^{18}$.

\section{Study Abroad Program Evaluation and Assessment}

The first step in creating an evaluation process of an International Program is to look at what is already in place in terms of assessment at the University. Joan Gillespie ${ }^{10}$ points to the importance of study abroad assessment in her article Colleges Need Better Ways to Assess Study Abroad Programs. In the 1970s, the assessment movement at U.S. Colleges and Universities shifted our focus from the institution to the student, from teaching to learning. In study abroad programs, we know now that our attention should focus on students as "intercultural learners" rather than academic tourists. Just like the Universities undergo regular assessment cycles to meet accreditation standards, international programs must also go through a regular evaluation in 
order to establish and maintain quality programs. The IIE of Students, based in Chicago has developed a process of evaluating study abroad programs. This model is divided into several areas: student environment, resources for academic support, and student learning. In the section on student learning, the Institute looks at academic achievement defined by mastery of course material, development of critical-thinking skills, language proficiency and intercultural competencies defined by measurements of cognitive, personal and social growth. Quality is measured by qualitative data such as students' awareness of cultural knowledge and quantitative data (such as the number and kind of opportunities that expose students to the local intellectual and material culture).

One of the key parts of evaluating the academic achievement in study abroad is to ask how much a program links its course work with fieldwork. Does a study abroad program engage students in their surroundings and take advantage of examining cultural values and differences that are unique to international study? The next question deals with whether instructors on International Programs make an effort to connect course work with insights of the region? To put emphasis on this point, William Anthony, Director of Study Abroad at Northwestern University in Evanston, Illinois writes “Internationalization and globalization don't magically happen by sending ever-higher number of students abroad. They take place in the minds of individual students as a result of challenging and active academic study and interaction on site". As far as Kettering University is concerned, the answer to these questions is 'yes' to a great extent. The German language (where offered) and the social science courses expose the students to the cultural, economic, political and industrial side of the local regions and the European Union, where as the technical courses taught by teachers with industry background certainly offers a chance for them to participate in organized industry tours and field trips as a part of the course.

Engineering study abroad programs have not put much importance on the value of language development, but language skills are a crucial part of evaluating the quality of a study abroad program. Quantitative measures of linguistic progress by using entry and exit tests and oral proficiency interviews are standardized ways of assessing academic achievement in international programs. Language learning is closely linked to a better understanding of the local culture.

Other topics in assessing technical study abroad programs include issues surrounding the grading scales and grading standards of the foreign institutions as part of the returning students' transcript. Usually at Kettering University we record the credit simply as "pass/ no pass" for the study abroad courses. The grading scale and grading standards vary from University to University. Some Institutions believe that student take a program more seriously if the grade is recorded, while others believe that students who take the challenge of studying abroad should not be punished with potential low marks from the institution abroad. The problem with assessment here is that by recording credit as pass/ no pass we eliminate a quantitative measure of assessment. Many other practical questions exist such as: Are there core experiences every study abroad student should share? What level of integration in the host culture is ideal (do the students live in dorms or with families?) How can a program compensate for students with beginning or no language skills? All of these questions are crucial for Universities embarking on the creation of a study abroad assessment plan. 
The process of creating an assessment plan is continuous and never-ending. It is, however, necessary in order to maintain the quality, integrity and ultimately maintain the respect of like institutions and accrediting bodies. The task at hand involves having a consistent assessment across international programs. Additionally, it requires adequate staff time and funds invested in the process so that evaluation is a regular part of the planning and operation of the study abroad programs. The following are some suggested criteria for evaluation. These criteria are intended to give focus and direction while allowing flexibility to Universities who tailor their own studyabroad programs:

- Does the program help to fulfill the institutions overall mission, general goals and strategic plan?

- What academic quality or distinction does the program provide?

- Is the program comparable in academic rigor to the home institution?

- What distinct advantage is given for basing the program abroad?

- What rationale is offered for the program's location?

- How desirable is such a program, given the institution's academic mission and the mission of cross-cultural education in general?

- Does the program take advantage of integrating the students' into the local culture, academic and social life?

- How available are the resources and support services abroad to ensure a viable program of high academic quality?

- What is the level of student and faculty interest and commitment in maintaining this particular kind of program?

The Task Force on Study Abroad of the American Association of Collegiate Registrars came up with criteria for program evaluation in four general areas:

a) Basic information:

- The adequacy and accuracy of printed materials

- The clarity of the program's objectives and the ways that the program and its location and resources contribute to the fulfillment of those objectives.

- Admissions requirements, their relation to the program's objectives, and the ways in which they are enforced.

b) Academic Aspects:

- How does the curriculum contribute to fulfilling the program objectives? How does it benefit from the host environment? How does it compare with the home curriculum in terms of level and degree of difficulty?

- What are the qualifications and attitudes of the faculty teaching the courses abroad?

- What are the academic resources (e.g., the library and laboratory facilities) How do they support the program's curriculum? 
c) Interaction with the Host Culture:

- Pre-departure materials and on-site orientation sessions: are they adequate?

- To what degree does the program promote and facilitate students' interaction with the host culture?

d) Administrative aspects:

- What is the extent and adequacy of administrative support at the home campus?

- How effective is the on-site support structure, including the resident director and administrative support staff?

- How is the program affiliated with the home/ host institution?

- Are there sufficient support services? (e.g., personal, academic advising, healthboth medical and psychological- services)?

- How much does the program cost and what will this include or not include? How accurate is the cost information available to the students?

- Are the travel arrangements adequate?

- Are the students provided the information regarding government related documents and information (e.g., passport, number of passport size photos to be carried, visa requirements to visit another foreign country, contact information about the nearest embassy, etc.)?

e) Sources of information:

- Survey Questionnaires to be sent out to students immediately upon their return from abroad. These can be very useful to receive student feedback on various aspects of the program.

- Interviews with returning students, on-site faculty and staff, the home campus's faculty and academic units, the study abroad staff and outside evaluation teams.

Due to the growing number of engineering students studying abroad there is an ever increase in need for standards to assess the academic quality of foreign programs. This need to evaluate the vigor of an academic program is particularly important if engineering exchanges are to grow throughout higher education. In addition to assessing the academic merit of the engineering curriculum, the unique qualities of international study make it necessary to take a look at other important factors of such an experience such as cultural and linguistic knowledge that students learn on an international exchange. Faculty oversight of such international programs is essential if the programs are to gain respect. The faculty should also play a central role in the evaluation and assessment of a study abroad program as a way of improving the quality of a program; not only for curriculum improvements, but factors such as how well do students adjust socially, linguistically and culturally are of equal importance.

As mentioned before, there are many other universities in the US that have developed study abroad programs. Since the benefits of such collaboration outweigh the difficulties, there is an ever increasing tendency for other universities to develop such programs. In looking at the literature presented in these papers, one can observe that not many universities have developed the course assessment tools necessary to evaluate the particular program and course educational objectives. Although currently there are no uniform guidelines to assess the individual study abroad programs by ABET, each of the participating Universities have developed their own 
assessment and evaluation tools necessary to justify their individual study abroad programs. The intention of this paper is to discuss the assessment and evaluation tools developed jointly by the author in consultation with both the current and the previous faculty coordinators of each study abroad program at Kettering University.

\section{Description of ME Study Abroad Experiences for Kettering University students}

Students who are eligible to the following partner universities in Germany are asked to take a maximum of sixteen credits, normally encompassing three ME and/or Technical courses and one Liberal Studies course, titled "Germany within Europe". This course corresponds to an Advanced Social Science course at Kettering, entitled "Topics in Social Science, SSCI 308. The language course, "German for Beginners" is for enrichment with no credits. The tables below exhibit the current programs with the course offerings:

\section{University of Esslingen Program (Spring and Fall Terms)}

\begin{tabular}{|l|l|l|}
\hline \multicolumn{1}{|c|}{ Courses } & \multicolumn{1}{|c|}{ Course Equivalence at KU } & \multicolumn{1}{c|}{ Pre- or co-requisites } \\
\hline Fluid Mechanics & Fluid Mechanics & Thermodynamics \\
\hline $\begin{array}{l}\text { Computer Simulation in } \\
\text { Automotive Engineering }\end{array}$ & $\begin{array}{l}\text { Dynamic Systems - I, or } \\
\text { Technical Elective }\end{array}$ & $\begin{array}{l}\text { Dynamics, Fluids, } \\
\text { Numerical Methods }\end{array}$ \\
\hline $\begin{array}{l}\text { Elements of Feedback } \\
\text { Control Technology }\end{array}$ & $\begin{array}{l}\text { Dynamic Systems - II, or } \\
\text { Technical Elective }\end{array}$ & $\begin{array}{l}\text { Dynamics, Numerical } \\
\text { Methods }\end{array}$ \\
\hline Introduction to German & No Credit & None \\
\hline $\begin{array}{l}\text { Introduction to German } \\
\text { and European History }\end{array}$ & Topics in Social Science & $\begin{array}{l}\text { COMM 101, SSCI 201 and } \\
\text { HUMN 201 }\end{array}$ \\
\hline Finite Element Analysis & ME Technical Elective & Solid Mechanics, CAE \\
\hline $\begin{array}{l}\text { Fatigue Analysis of Car } \\
\text { Structures }\end{array}$ & ME Technical Elective & $\begin{array}{l}\text { Machine Design, } \\
\text { Mechatronics }\end{array}$ \\
\hline
\end{tabular}

University of Konstanz (Spring Term)

\begin{tabular}{|l|l|l|}
\hline \multicolumn{1}{|c|}{ Courses } & \multicolumn{1}{|c|}{ Course Equivalence at KU } & \multicolumn{1}{c|}{ Pre- or co-requisites } \\
\hline $\begin{array}{l}\text { Design of Mechanical } \\
\text { Components }\end{array}$ & Machine Design - I & Solid Mechanics \\
\hline Fluid Mechanics & Fluid Mechanics & Thermodynamics \\
\hline Germany with in Europe & Topics in Social Science & $\begin{array}{l}\text { COMM 101, SSCI 201 and } \\
\text { HUMN 201 }\end{array}$ \\
\hline Finite Element Analysis & ME Technical Elective & Solid Mechanics, CAE \\
\hline Heat Transfer & Heat Transfer & Fluids, Thermodynamics \\
\hline $\begin{array}{l}\text { Introduction to } \\
\text { Automotive Powertrains }\end{array}$ & Powertrains & Solid Mechanics \\
\hline
\end{tabular}


Munich University of Applied Sciences (Spring Term)

\begin{tabular}{|l|l|l|}
\hline \multicolumn{1}{|c|}{ Courses } & \multicolumn{1}{c|}{ Course Equivalence at KU } & \multicolumn{1}{c|}{ Pre- or co-requisites } \\
\hline $\begin{array}{l}\text { Automatic Control } \\
\text { Systems }\end{array}$ & $\begin{array}{l}\text { Dynamic Systems - II, or } \\
\text { Technical Elective }\end{array}$ & $\begin{array}{l}\text { Dynamics, Numerical } \\
\text { Methods }\end{array}$ \\
\hline Fluid Mechanics & Fluid Mechanics & Thermodynamics \\
\hline Introduction to German & No Credit & None \\
\hline $\begin{array}{l}\text { Solids Based Modeling for } \\
\text { FEA }\end{array}$ & $\begin{array}{l}\text { FEA, or ME Technical } \\
\text { Elective }\end{array}$ & Solid Mechanics, CAE \\
\hline $\begin{array}{l}\text { Thermal Fluid Power } \\
\text { Systems Laboratory }\end{array}$ & Energy Systems Laboratory & Fluids, Thermodynamics \\
\hline $\begin{array}{l}\text { Internal Combustion } \\
\text { Engines }\end{array}$ & $\begin{array}{l}\text { Internal Combustion Engines, } \\
\text { or Technical Elective }\end{array}$ & Thermodynamics \\
\hline
\end{tabular}

University of Applied Sciences Ulm (Fall Term)

\begin{tabular}{|l|l|l|}
\hline \multicolumn{1}{|c|}{ Course } & Course Equivalence at KU & \multicolumn{1}{|c|}{ Pre- or co-requisites } \\
\hline Fluid Mechanics & Fluid Mechanics & Thermodynamics \\
\hline Process Automation & Dynamic Systems - II & Dynamic Systems - I \\
\hline CAD/ CAM & ME/ Technical Elective & CAE \\
\hline Fuel Cell Principles & ME/ Technical Elective & Fluids \\
\hline $\begin{array}{l}\text { Applied Thermal-Fluid } \\
\text { Systems }\end{array}$ & $\begin{array}{l}\text { Energy Systems Lab., or } \\
\text { ME Tech. Elec. }\end{array}$ & Fluids \\
\hline German for Beginners & No Credit & None \\
\hline Germany within Europe & $\begin{array}{l}\text { SSCI 303 Topics in Social } \\
\text { Science }\end{array}$ & $\begin{array}{l}\text { COMM 101, SSCI 201 and } \\
\text { HUMN 201 }\end{array}$ \\
\hline
\end{tabular}

\section{Implementation Plan and Assessment:}

The Study Abroad programs are approved on a departmental basis with consultation and cooperation of the other participating departments such as Liberal Studies department. For example, the department of Mechanical Engineering at University of Esslingen in Germany would have a list of courses which affect our ME students and therefore the department at Esslingen would be approved as a whole rather than approving each and every course. There are one or two faculty members assigned to oversee each Study Abroad program (advisor) who are responsible for advisement, mentoring, monitoring and assessment of that program. Ahead of time, the program coordinator pre-determines, in consultation with appropriate faculty, which courses will transfer directly back to Kettering as if courses were taken at Kettering University. Assessment of course is therefore needed. No two courses of the same title are taught the same way in different parts of the world. The assessment process is carried out via course portfolios and a competency matrix (end-of-course outcomes-based survey-). Students are asked to compile course portfolios and keep track of assignments, notes, HW, reports, projects, etc. Individually, students are asked to fill out course evaluations and a competency matrix rating the contribution of the course in helping them achieve certain outcomes. These outcomes are the 
program educational outcomes of the ME program at Kettering University. Operational elements of the study-abroad programs are as follows:

- Students are advised as a group by the program coordinator (typically one or two terms in advance and approximately six months to one year prior to going abroad. Although advising them individually is an inefficient use of time, it is still much prevalent due to their very tight schedule.

- Students are informed six months to one year prior to travel by the Director of study Abroad Programs at Kettering University, how the transfer of courses is going to occur and the correspondence (equivalence) of courses taken abroad with Kettering courses.

- Students are asked to fill out a competency matrix (outcomes-based survey) rating the contribution of each course taken abroad to their achievement of certain outcomes.

- Students are asked to fill out an end of the term course and program evaluations.

- Students are asked to write an essay documenting the usefulness and contribution of the course to their professional and personal growth.

- Students are asked to itemize a list of recommendations for the purpose of program improvement.

- Students' grades will be sent directly and officially from the program abroad to the Director of Study Abroad Programs at Kettering University. The Director would then inform the registrar about the courses and associated grades. Every Study abroad program must make the passing grade clear to the students while attending their courses and also to the coordinator and registrar at Kettering University.

- Students are viewed as ambassadors and true representatives of Kettering University. Therefore only qualified (students with an $85 \%$ WAG or above) are encouraged to participate in various study abroad programs.

\section{Course Portfolios}

The following information is sent to students, typically via e-mail both before and during their study abroad term:

1. Keep a Portfolio for each course that contains a collection of each course notes and students' work (assignments, exams, projects, etc) exhibiting the achievement of certain skills and abilities. They also fill out a "competency matrix" upon completion of the course, to help students reflect on their learning. This matrix features specific outcomes, of which the course may target some, and provides the ME program with students' perception on where and how these outcomes were achieved. All students are expected to submit this portfolio up on return from a study abroad program directly to the Director of Study Abroad Programs.

2. A meeting will take place (students and coordinator) on a certain convenient day during the terms following the study abroad term at Kettering to discuss lessons learned and potential areas for improvement.

3. Formulate and list any recommendations for the improvement of the study abroad program. 


\section{Lessons Learned}

We have learned several lessons at Kettering University over that last several years regarding the improvement and expansion of study abroad programs. These lessons will be important to us in terms of creating a relevant assessment program for international programs. Many of these areas are unique to Kettering University such as the limits that our academic calendar put on students who want to study abroad. The academic calendar at Kettering makes it particularly difficult to send a large number of students abroad. The academic year is divided into four eleven week quarters. Students are divided into two sections: A-Section and B-Section. There are very few schools abroad (or even within the USA) that can accommodate this calendar, meaning that most programs must be tailor-made to fit the Kettering calendar requirements. The reality at Kettering University is that the majority of students study abroad in the Spring term (April to June) since that is when most of our foreign partners can provide accommodate with minimum problems. A final lesson that we have learned is that we must do a better job at balancing the numbers of students who go on one program versus another. In the past years, our study abroad programs either had too little or too many students. As a result, we are trying to create a system that more adequately balances the number of students on various programs.

We are currently creating a more systematic approach to advising for study abroad. The advisor meets with the students to discuss course pre-requisites, courses abroad and courses when the students return to Kettering University. We communicate through an International Programs Committee (IPC) consisting of Faculty and Administrative staff. The IPC is a useful forum where students, faculty and administration can come together to communicate their efforts at Internationalizing Kettering. This committee was born as a result of what we learned from different offices and departments taking on International Activities without consulting with other parts of the University. In addition, it joins the various departments and offices that conduct International activities. An evaluative process is still not in place for all of these areas, but we know that we must create a process that will address these areas fully to help us improve the programs. With the newly proposed international programs structure at Kettering (as shown in Fig. 1), we anticipate a more streamlined system of activities with equitable distribution of efforts put in by the faculty and the staff to promote the study abroad activities.

\section{Conclusion}

In conclusion, the numbers of engineering students who participate in international academic exchanges is growing rapidly. More students within the mechanical engineering field are asking for and going on study abroad programs where they take a term to study coursework at a foreign university. The academic standards at the time of applying to study abroad and to pass the courses taken abroad, has been raised to around $85 \%$. The Evaluation and assessment procedures for these study abroad programs will ensure that the quality and reputation of such programs remains high. Provided that the faculty, administration and students are involved in the creation, maintenance and evaluation of such programs, there is no reason why these programs will not be able to grow and flourish. Assessment and evaluation of programs will make international programs a more convincing option for faculty and ultimately benefit the students in creating the highest quality study abroad programs. 


\section{Acknowledgment}

The authors acknowledge the support of their colleagues in Germany (Esslingen, Ulm, Konstanz and Munich). Without their guidance and oversight, these programs simply would not have taken shape. Additionally, the first author wishes to acknowledge support provided by Kettering University's International Programs Division and the Oswald faculty grant.

\section{Bibliography}

1. Nasr, K., et al., "Global Engineering Education Through Study-Abroad Experiences: Assessment and Lessons Learned", Proceedings of the 2002 ASEE/SEFI/TUB Colloquium, Berlin, 2002.

2. Engle, J. "Creating More Rigorous and Appropriate Study-Abroad Programs", The Chronicle of Higher Education, 17 March 1995, A56.

3. http://www.daad.org/

4. http://www.iie.org/

5. "The Bologna Declaration on the European space for higher education: an explanation", http://europa.eu.int/comm/education/policies/educ/bologna/bologna.pdf.

6. "What is Erasmus?", http://www.erasmus.ac.uk/whatis.html

7. Pathomvanich, S., and Najafi, F. T., "International Partnership in Engineering Education", Proceedings of ASEE2001.

8. Chen, C. C., and Simmons, L. F., "International Project and Education Cooperation Experience with Alexandria University in Egypt", Proceedings of ASEE2001.

9. Upadhyaya B. R., and Kerlin, T. W., "International Collaboration on Cyber-linked Engineering Projects", Proceedings of ASEE2001.

10. Mazumdar, A., and Bean, J., "A Global Concentration in Engineering", Proceedings of ASEE2001.

11. Global Engineering Education: A Partnership between Rajagiri College (Cochin, India) and Old Dominion University (Norfolk, VA), Proceedings of ASEE2001.

12. Chaturvedi, S., Crossman, G., Swart, W., and Betit, J., "Global Engineering in an Interconnected World: An Upper Division General Education Cluster at Old Dominion University", Proceedings of ASEE2001.

13. Going Global - A Methodology of Shaping Students for the Global Workplace by R.E. Thompson and R. Sterkenburg, Proceedings of ASEE2001.

14. Rogers, H., "A New Paradigm for Student Exchange and Globalization", Proceedings of 2002 ASEE/TUB/SEFI Colloquium, Berlin, 2002.

15. Petersen, O. et al, "ABET Accreditation of an International Us-German Degree Path", Proceedings of 2002 ASEE/TUB/SEFI Colloquium, Berlin, 2002.

16. Brito, C. da R., Ciampi, M. M., Zakharov, V. G., and Avenarius, I. A., "The Importance of Collaborative Work Among Countries in Engineering Education”, Proceedings of ASEE 2006 Conference held in Chicago, paper \#1615, June 2006.

17. Bohn, J. H., and Hampe, M., "Study Abroad Programs in Mechanical Engineering", Proceedings of ASEE 2006 Conference held in Chicago, paper \#1619, June 2006.

18. Bradley University Study Abroad Programs: http://studyabroad.bradley.edu/january/currentprogram.html 


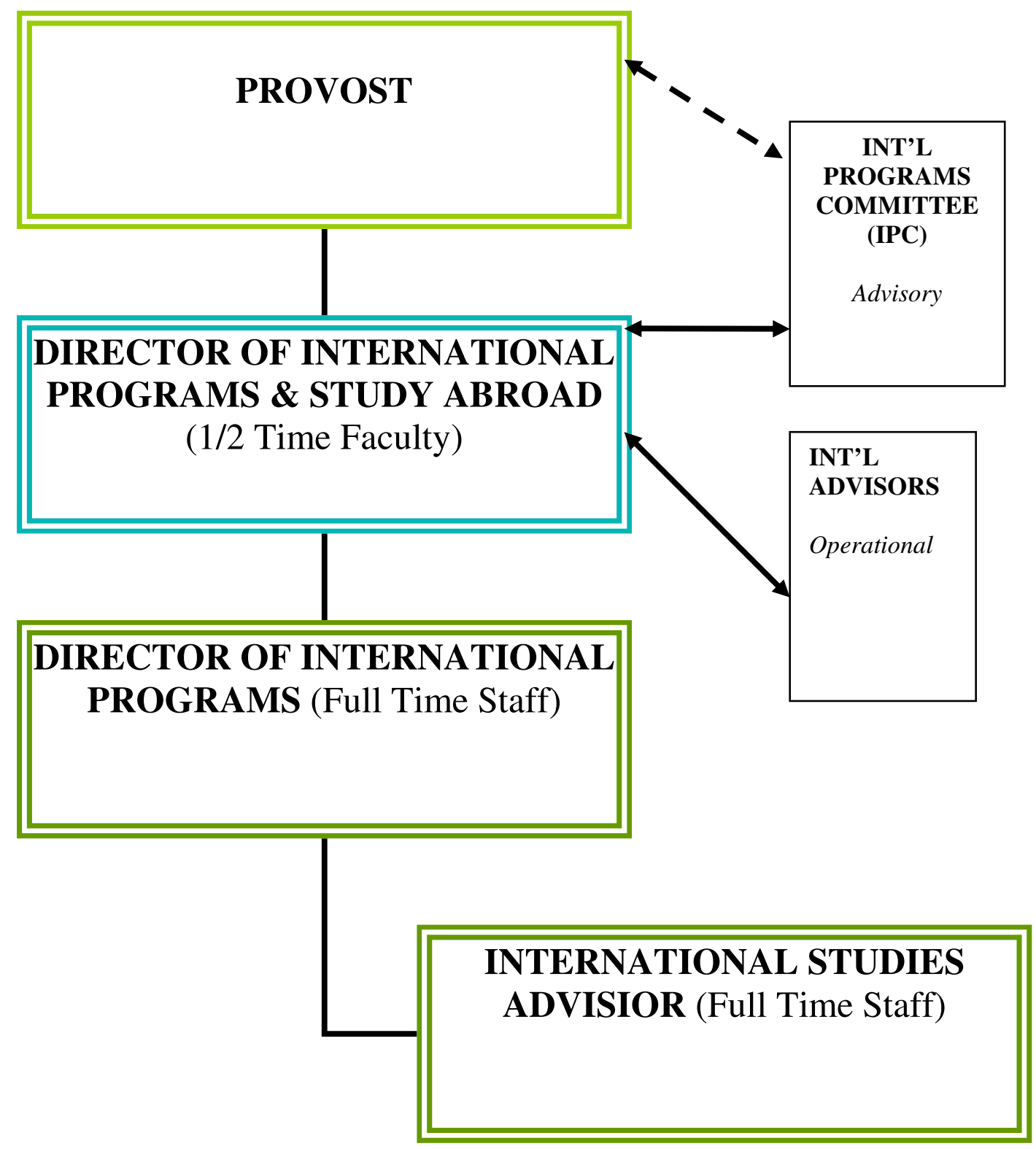

Fig. 1: Proposed office structure of International Programs at Kettering University 